\title{
PRESERVAÇÃO DO PATRIMÔNIO ARQUEOLÓGICO: CONSERVAÇÃO DO SÍTIO RUPESTRE PEDRA DO NAVIO, PARANATAMA, PE
}

\author{
Neuvânia Curty Ghetti ${ }^{1}$, Cláudia Alves de Oliveira ${ }^{2}$ \\ 1 - Química, Professora Departamento de Arqueologia, CFCH, UFPE; 2 - Arqueóloga, Professora Departamento de Arqueologia, CFCH, UFPE \\ curty.quimicarqueologica@gmail.com
}

Resumo: O Sítio Arqueológico Pedra do Navio apresenta pinturas rupestres em um paredão granítico, identificadas como pertencentes à Tradição Agreste no estilo Cariris Velhos, com grafismos puros e grafismos de composição, predominando a cor vermelha e amarela em vários tons. Na realização do Diagnóstico para a Conservação foram trabalhados os sete painéis com vestígios de pinturas rupestres. Os objetivos deste trabalho foram realizar diagnóstico e mapeamento de danos para definir ações de conservação e realizar limpeza investigativa nos pontos críticos e com urgente risco ao Patrimônio Arqueológico. Como resultados apresentam-se elementos revelados pelo diagnóstico do estado de conservação, sistematicamente organizados e incluindo a identificação e dos fatores, mecanismos e indicadores visuais de degradação para as pinturas, assim como os efeitos obtidos nas ações preliminares de limpeza e conservação.

Palavras Chave: conservação, sítio rupestre, Pedra do Navio.

Abstract: PRESERVATION OF ARCHAEOLOGICAL HERITAGE: CONSERVATION OF THE PEDRA DO NAVIO RUPESTRE SITE, PARANATAMA, PE. The Archaeological Site "Pedra do Navio" show paintings supported by a granite wall identified as belonging to the "Agreste" tradition, "Velho Cariris" style, with pure and composed graphics, predominantly red and yellow colors in various shades. The objectives of this study were to perform a diagnosis and damage mapping in order to define archaeological conservation actions and to conduct an investigative cleaning at the critical points, with urgent risk to the Archaeological Heritage. As results, we present the elements revealed by the diagnosis of conservation status, systematically ordered including the identification of factors, mechanisms and visual indicators for degradation of the paintings, and the effects obtained in the preliminary actions of conservation and cleaning.

Keywords: conservation, rock art paintings, archaeological site, "Pedra do Navio"

\section{INTRODUÇÃO}

O Sítio Arqueológico Pedra do Navio destaca-se como Patrimônio Natural e Histórico-Cultural, sendo amplamente reconhecido como tal pela comunidade local e pela comunidade acadêmica e científica. Está registrado no Instituto do Patrimônio Histórico e Artístico Nacional (IPHAN), no Cadastro Nacional de Sítios Arqueológicos - CNSA PE00150.

As atividades de Limpeza e Conservação no Sitio Arqueológico Pedra do Navio/ Paranatama inseremse no âmbito do Projeto de Resgate Arqueológico e Educação Patrimonial na Área de Implantação da Linha de Transmissão 230 kV SE que atravessa os municípios de Caetés, Garanhuns, Jucati, Paranatama e São João, no estado de Pernambuco. Assim, reforça-se a relevância dos trabalhos de conservação aplicados nesse patrimônio materializado na pedra.

De acordo com os resultados apresentados no projeto supracitado, o reconhecimento desse patrimônio está fortemente presente nas comunidades e integrado na forma cotidiana de viver e construir cada lugar. Isto pode ser notado, ainda, pelo fluxo turístico em alguns dos municípios estudados, remetendo ao importante contexto histórico e cultural regional, ligado aos processos de uso e transformação do espaço, constituindo uma paisagem cultural que necessita ser contemplada em pesquisas futuras.

\section{CONSERVAÇÃO DE SÍTIOS RUPESTRES: UMA ABORDAGEM INTERNACIONAL}

A ação de intervenção para a conservação dos sítios rupestres fundamenta-se no reconhecimento rigoroso e interdisciplinar do sítio como parte preliminar do trabalho e concordante com o quadro teórico universal. Destacam-se as recomendações das Cartas Patrimoniais (2000) que definem os princípios internacionais a serem aplicados em matéria de pesquisa arqueológica, como os destacados pela Conferência em Nova Delhi, de 1956. A Norma de Quito de 1967 versa sobre a conservação e a utilização de monumentos e sítios de interesse histórico e artístico e considera a valorização de monumentos e sítios em função do turismo e do interesse social. A Carta de Restauro Itália, 1972 - no seu Anexo A, estabelece instruções para a salvaguarda e conservação dos sítios arqueológicos, considerando a conservação preventiva e a capacidade de carga para os visitantes dos sítios. Na Carta para a proteção e a Gestão do patrimônio arqueológico - Lausanne, 1990, o patrimônio arqueológico constitui testemunho essencial sobre as atividades humanas do passado e sua proteção e gerenciamento são, portanto, indispensáveis para permitir aos arqueólogos e outros cientistas estudá-lo e interpretá-lo, em nome das gerações presentes e futuras e traça diretrizes para intervenções no sítio arqueológico levando em consideração as degradações causadas nestes por agentes naturais, entre outros. Do Art. 20 da Carta de Veneza de 1964, destaca-se que a conservação dos monumentos exige, antes de tudo, manutenção permanente e 
considera que a proteção do patrimônio arqueológico constitui um processo dinâmico e permanente e entende que devem existir programas de cooperação internacional, pois o patrimônio arqueológico é uma herança comum a toda a humanidade.

Consideramos que a arte rupestre surgiu a partir da capacidade que o homem teve de colocar em prática uma ideia, valendo-se da faculdade de dominar a matéria - a pedra. Esta atividade que supõe a criação de sensações ou de estado de espírito, de caráter estético e carregada de vivência pessoal e profunda, pode suscitar o prolongamento de sua renovação.

Verifica-se, assim, a necessidade de se desenvolver, um processo metodológico orientado para a conservação deste substrato pétreo voltado para sua estabilização, procurando determinar as causas dos agentes de deterioração e suas patologias, visando estabelecer diretrizes, normas, responsabilidades e obrigações no intuito de preservar o Sítio Rupestre como documentomonumento, que, por vezes encontra-se em processo de degradação.

\section{ESTUDOS DE CONSERVAÇÃO: INTERVENÇÕES NO SÍTIO ARQUEOLÓGICO PEDRA DO NAVIO}

As intervenções para conservação no Sítio Arqueológico Pedra do Navio em Paranatama envolveram três momentos: a primeira etapa caracterizou-se como de diagnóstico do estado de conservação, com identificação preliminar das causas do processo de deterioração; a segunda etapa voltou-se para a definição das ações de intervenção para a conservação; e a terceira etapa buscou a realização da limpeza investigativa nos pontos críticos e com urgente risco ao Patrimônio Arqueológico.

\subsection{O Município de Paranatama e o Sítio Arqueológico Pedra do Navio}

\subsubsection{Alguns aspectos fisiográficos do município}

De acordo com os dados fornecidos pelo Centro de Pesquisa em Recursos Minerais-CPRM (2005), o município de Paranatama, está inserido na unidade geoambiental do Planalto da Borborema, formada por maciços e outeiros altos, com altitude variando entre 650 a 1.000 metros. O clima é do tipo Tropical Chuvoso, com verão seco. A estação chuvosa se inicia em janeiro/fevereiro com término em setembro, podendo se adiantar até outubro. Geologicamente, o município de Paranatama encontra-se inserido, na Província Borborema, sendo constituído pelos litotipos dos complexos Cabrobó e Belém do São Francisco, dos granitóides indiscriminados e de quimismo indiscriminado.

\subsubsection{Arqueologia do Sítio Pedra do Navio}

O sítio arqueológico Pedra do Navio é caracterizado por pinturas rupestres que aparecem no paredão granítico e foram identificadas pela pesquisa arqueológica (Aguiar, 1996), como pertencentes à Tradição Agreste, no estilo Cariris Velhos, com grafismos puros e grafismos de composição. De acordo com Aguiar (1996), estes cariris aparecem em áreas onde os granitos, de granulação média a grossa e de cor acinzentada, constituem importantes intrusões que, pelo efeito da erosão nas rochas mais brandas encaixantes, emergem na forma de grandes monólitos arredondados onde geralmente se encontram as pinturas rupestres.

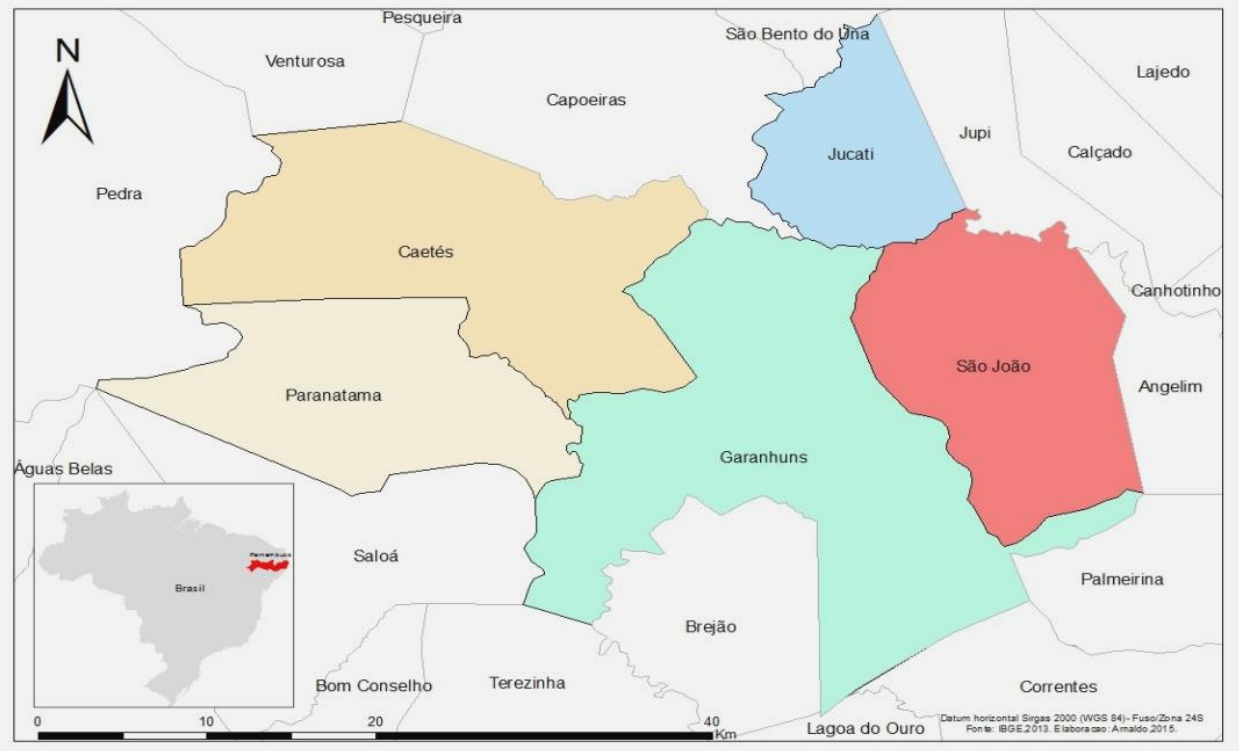

Figura 1. Região micro geográfica de Garanhuns- PE, onde está inserido o município de Paranatama. Fonte: CPRM, 2005. 
Segundo Aguiar (1996), na Tradição Agreste predomina a cor vermelha em vários tons aparecendo também o amarelo. De modo geral, as tintas utilizadas nas pinturas rupestres da Tradição Agreste provêm de pigmentos de natureza mineral, sendo o mais comum o Ocre $\left(\mathrm{Fe}_{2} \mathrm{O}_{3} \mathrm{XH}_{2} \mathrm{O}\right)$, argila colorida por Óxido de Ferro, que se apresenta nas cores vermelha e amarela. A pesquisa arqueológica em 1996 identificou quatro painéis e um abrigo e registrou a possibilidade para escavação arqueológica. Na realização do Diagnóstico para Conservação foram identificados mais 03 painéis com vestígios de pinturas rupestres e mais um painel com possibilidades de apresentar grafismos, uma vez que no levantamento arqueológico realizado em 1996constatou-seque a pedra em forma de "navio" (ver Figura 2) deveria conter muitas pinturas, mas a esfoliação natural da rocha, aliada às ações antrópicas, como o uso de dinamite em 1964, causaram a destruição da maioria das pinturas.

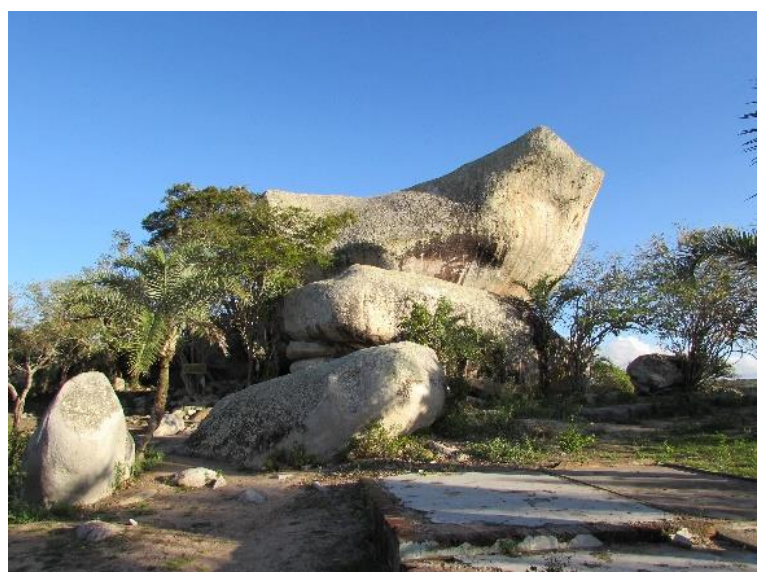

Figura 2. Vista frontal da Pedra do Navio.

3.2. Diagnóstico de Conservação para o Sítio Arqueológico Pedra do Navio
Para a elaboração de um diagnóstico de conservação e mapeamento dos painéis com pintura rupestre e seus danos, com o objetivo de registrar o estado de conservação, partiu-se da análise de situação por meio da elaboração das Fichas de Identificação de Danos (FIDs), que formaram uma base de dados para cada painel, relacionando a intensidade do dano, o tipo e os indicadores visuais de alteração, apresentadas em forma de um formulário. A partir do diagnóstico realizado, é possível discriminar os procedimentos técnicos de conservação específicos para a preservação desse patrimônio arqueológico.

Podemos destacar que esta primeira etapa contou com a experiência multissensorial de interação com o lugar -o Sítio, e esse conhecimento vem a partir de estudos in loco que passam pela ambiência do sítio e vão além do sentir e do perceber, para realmente compreender o sítio e construir um entendimento dos impactos sofridos.

A representação gráfica produzida é elaborada para utilização como suporte às intervenções de conservação no patrimônio arqueológico, sendo uma comunicação visual que objetiva evidenciar as relações fundamentais entre o suporte rochoso, a pintura e os danos, registrando a diversidade, a hierarquização e as evidências quantitativas que serão transcritas pelas relações visuais apresentadas. De acordo com Tinoco (2009), toda representação gráfica implica uma forma de ver e conceber a realidade, a qual é tratada cientificamente através da opção pessoal de determinados pressupostos teóricos e metodológicos.

A seguir, observa-se um esboço com o esquema do Sítio Pedra do Navio em vista superior, seus painéis rupestres e pichações.

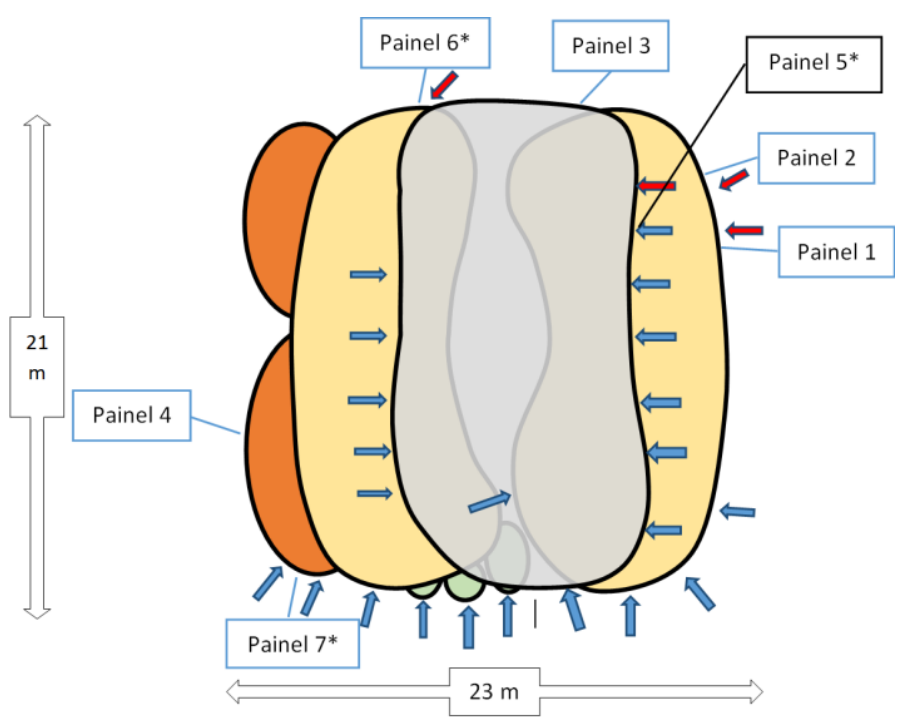

Figura 3. Painéis com pinturas rupestres e pichações mapeadas. Em vermelho: pichações sobre painéis com pintura rupestre (críticas). Em azul: principais pichações presentes no sítio rupestre. *Painéis identificados pelo diagnóstico de conservação. 


\subsubsection{Diagnóstico de situação}

Em sequência, apresenta-se um descritivo das alterações verificadas na relação suporte rochoso e painéis com pintura rupestre. Estas alterações estão relacionadas aos indicadores visuais de alteração e foram registrados nas FIDs, consideradas unidades de informação neste mapeamento para diagnóstico. As pichações ocorrem em profusão no entorno das rochas que compõem o sítio sendo em cores e pigmentos diversos e a presença de biocrosta formada de líquen e musgos é constatada em várias áreas do suporte rochoso.

Nos Painéis 1 e 2constatou-se a presença de pichação na cor branca, de composição em resina, água, pigmento e carga (sinonímia: corretivo líquido). No painel 3 constatou-se a presença de ninhos e casulos de marimbondos e vespas. No Painel 5 ocorreu uma grande concentração de pichações em cores e tintas diversas. No Painel 6 registrou-se a presença de biocrosta e pichação na cor vermelha de natureza alquídica/acrílica e pigmentos orgânicos e inorgânicos. No Painel 4 e no Painel 7 não foram identificados indicadores visuais de alteração para os painéis com grafismos rupestres que justificassem uma intervenção direta nos mesmos.

Observou-se, também, a área de entorno do sítio arqueológico e constatou-se a presença de remanescentes do piso de uma edificação demolida por ordem judicial. Constatou-se, ainda, que o acesso de visitantes ao local é livre e não controlado, que há presença de vegetação invasiva e acúmulo de lixo no local, e que a sinalização é inexistente.

\subsubsection{Identificação preliminar das causas do processo de degradação}

Parte-se do princípio que existe a interação de uma série de fatores de degradação de ordem interna (fatores intrínsecos) e externa (fatores extrínsecos) como determinantes no caráter dinâmico da deterioração natural e antrópica dos componentes da rocha suporte do paredão e das pinturas rupestres.

De acordo com Licth (1998), destacam-se como fatores intrínsecos, a localização geotopográfica do paredão ou abrigo, determinando a sua resistência físico-mecânica, a fadiga da pedra, cuja fragilidade e deterioração é acentuada pelo intemperismo na zona geológica e as técnicas pictóricas de pouca consistência pelo uso de aglutinantes orgânicos, apesar da natureza inorgânica dos pigmentos, são mais passíveis de sofrer degradações e manchamentos.

Para os fatores extrínsecos, destacam-se, a erosão - ação direta do vento procedente que evidencia a deposição microbiológica por carreamento eólico, a erosão pluvial do substrato pétreo ante à inclinação do suporte, a meteorização das pedras pela ação da insolação direta e da variação de temperatura e a ação de visitantes e turistas frente ao estado de extrema exposição do conjunto.

Considerando os autores Lage, Borges \& Rocha Júnior (2005) temos a atuação dos seguintes agentes de degradação que podem estar atuando nas alterações apresentadas pelo Sítio Pedra do Navio: a umidade, a biocrosta e a insolação.

A umidade que de forma pontual e externamente pode ser lançada pelos ventos contra a superfície rochosa, cria condições favoráveis ao aparecimento de líquens. Essa umidade presente, em equilíbrio com o material pétreo, pode indicar que o material irá, em função de alterações de temperatura, liberar umidade através da superfície, lixiviando elementos solúveis da sua constituição com formação de pátina, além de sofrer variações volumétricas.

A presença de microrganismos depositados por carreamento eólico nas superfícies do suporte, pode decorrer da ausência de vegetação alta nas proximidades o que facilita a direta atividade dos ventos com o aporte de matéria orgânica necessária para o assentamento de outros organismos como fungos, liquens.

Quanto à insolação, observa-se que em alguns painéis os raios solares passam tangencialmente, causando poucos danos pela ação de exposição direta. Em outros, a ação direta do sol, pode ter causado a perda da cor das pinturas pela oxidação do material orgânico aglutinante dos pigmentos.

Sendo assim, as patologias possíveis de serem observadas no levantamento de danos para o sítio rupestre Pedra do Navio, geralmente manifestam-se por: presença de pichação; mudanças da tonalidade original e pela presença de crostas biológicas.

\section{PRINCIPAIS INTERVENÇÕES REALIZADAS}

No entorno da Pedra do Navio, foram realizadas ações para limpeza preliminar geral da vegetação invasiva e do lixo. Para intervenções nos painéis foram empreendidas as ações apresentadas a seguir:

Painéis 1 e 2- pichação em área contígua ao grafismo rupestre: efetuada limpeza da pichação na cor branca, após investigação da natureza da tinta/pigmento e remoção com aplicação de compressa em matriz hidrossolúvel (Figuras 4 e 5).

Painel 3 - Insetos e casulos sobre os grafismos rupestres: efetuou-se a retirada de ninhos e casulos de marimbondos e vespas, por remoção mecânica e compressa hidrossolúvel (Figura 6). 


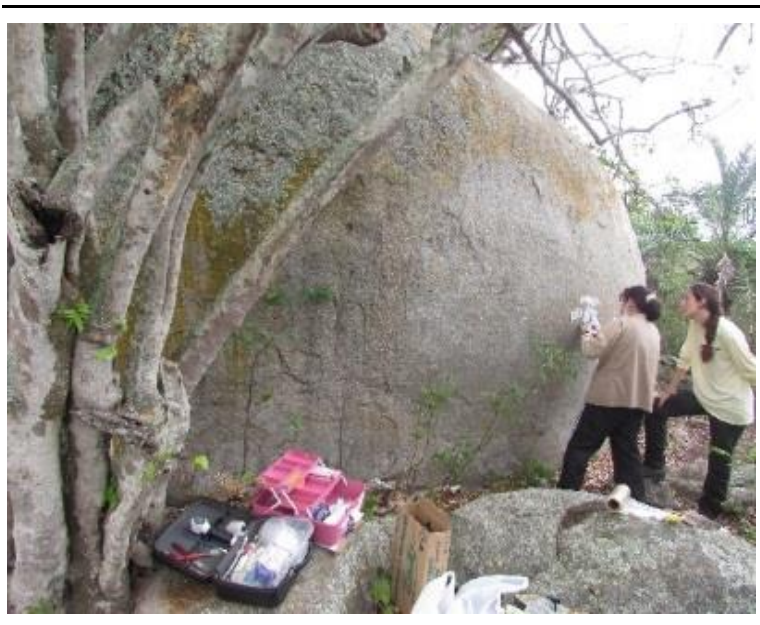

Figura 4. Limpeza do painel 1.

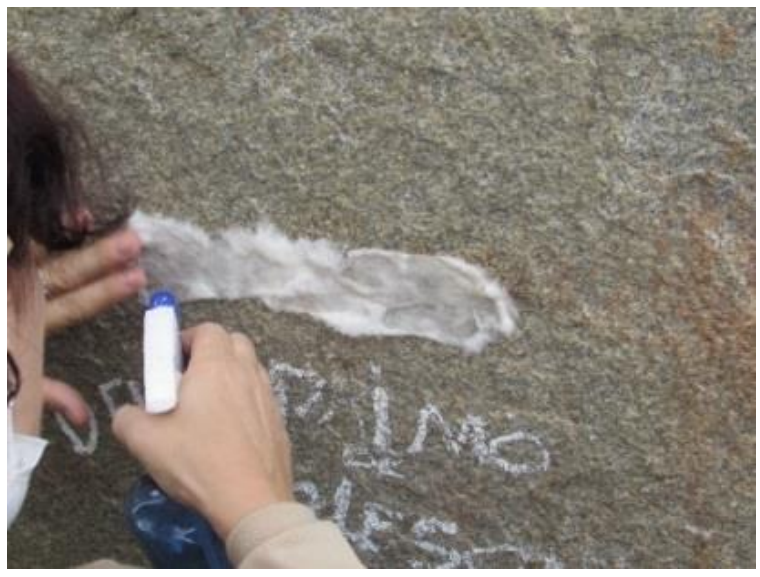

Figura 5. Limpeza do painel 2

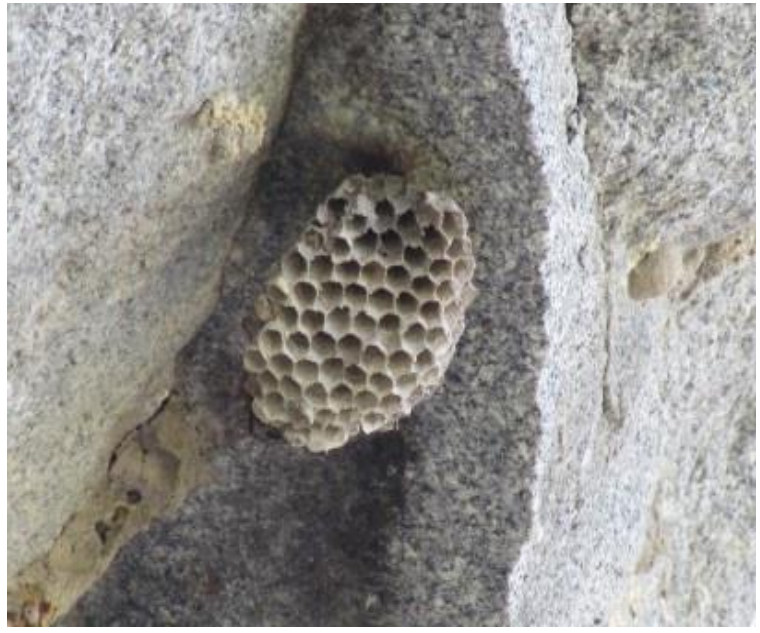

Figura 6. Limpeza do painel 3

Painel 5 - Grafismos rupestres afetados parcialmente por pichação: foram realizados testes por remoção mecânica, escovação e lavagem e ensaios com carta de solventes orgânicos e inorgânicos para definição de solvente/ agente de remoção nas pichações fixadas diretamente à rocha. Foi efetuada a remoção da pichação com aplicação de compressa em matriz hidrossolúvel (Figura 7).

Painel 6 -Grafismos rupestres sob a biocrosta e parcialmente afetado por pichação: foi realizado teste com carta de solventes e ensaios por decapagem aplicando adesivo em diversas matrizes com natureza em polihidrocarboneto esterificado para remoção da pichação e foi efetuada a aplicação de compressa em matriz hidrossolúvel para remoção da biocrosta (Figura 8).

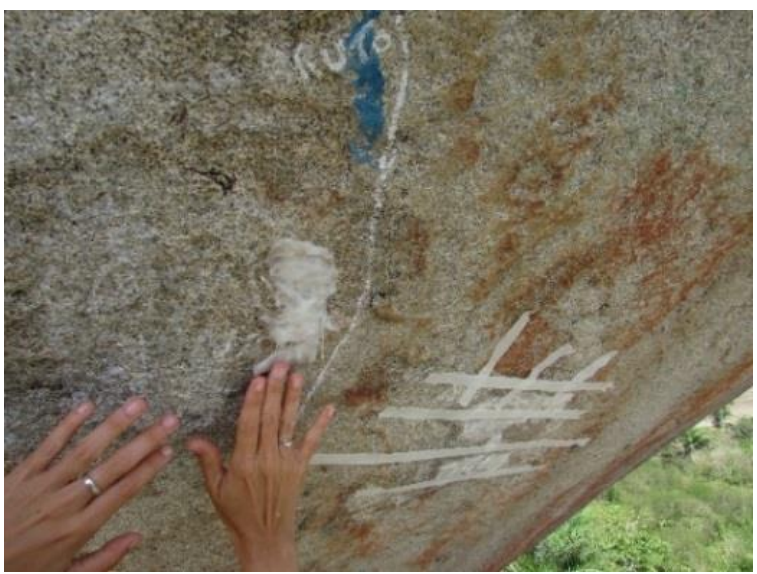

Figura 7. Limpeza do painel 5

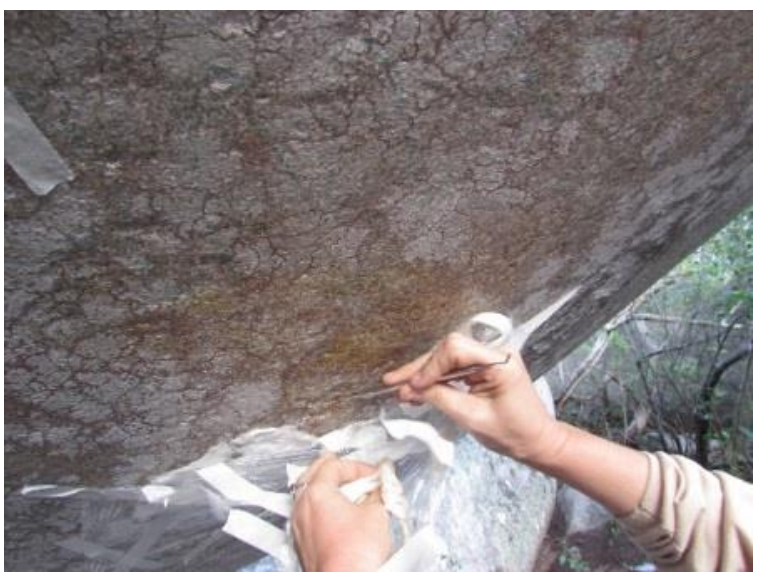

Figura 8. Limpeza do painel 6

\section{CONSIDERAÇÕES FINAIS}

Entendemos que as ações realizadas nesse trabalho não esgotam o assunto, uma vez que se voltaram ao estudo diagnóstico e à execução dos procedimentos urgentes e críticos, focados no patrimônio rupestre identificado e registrado no IPHAN, em processo de degradação e sob ameaça de perda.

Para a preservação e conservação do Sítio foram empreendidas ações indiretas como a instalação de sinalização (placa interpretativa)e a instalação de coletores de lixo em locais estratégicos. Durante a execução dos trabalhos de limpeza e conservação arqueológica no Sítio Pedra do Navio, foram realizadas ações de educação patrimonial junto aos moradores do entorno do sítio e aos visitantes das cidades vizinhas que usam a área do sítio para lazer.

Como conclusão, a sequência do trabalho requer a prática de outras ações, como uma necessária 
elaboração de rotina de manutenção do Sítio Arqueológico, considerando como subsídios o diagnóstico efetuado assim como a manutenção preliminar empreendida.

\section{REFERÊNCIAS BIBLIOGRÁFICAS}

AGUIAR, Alice. A Tradição agreste: estudo sobre Arte Rupestre em Pernambuco. Revista Clio Arqueológica. UFPE: Recife,1986.

CARTAS PATRIMONIAIS. Isabelle Cury (Org.) 2a ed. Revista e aumentada. IPHAN: Rio de Janeiro, 2000.

CPRM/PRODEEM - Serviço Geológico do Brasil. Diagnóstico do município de Paranatama, estado de Pernambuco / Organizado [por] Mascarenhas, J.C., et al. Recife, 2005.

LAGE, M.C.S.M, BORGES, J.F. \& ROCHA JÚNIOR, S. Sítios de Registros Rupestres: Monitoramento e Conservação. Revista Mneme. Revista de Humanidades. Dossiê Arqueologias Brasileiras. v.6, n. 13, dez.2004/jan.2005. Disponível em http://www.seol.com.br/mneme
LICHT, Otavio Augusto Boni. Prospecção geoquímica. Principais técnicas e métodos. Rio de Janeiro: CPRM, 1998.

TINOCO, J.E.L. Mapa de Danos- Recomendações Básicas. Textos para Discussão- Série 2: Gestão de Restauro. Centro de Estudos Avançados da Conservação Integrada-CECl: Olinda, 2009.

Contribuição ao

1‥ Simpósio Brasileiro de Caracterização e Conservação da Pedra 14 a 16 de dezembro de 2016, Congonhas - MG

Nota:

É de responsabilidade da comissão editorial do Simpósio a revisão gramatical, ortográfica, de citações e referências bibliográficas. As normas de submissão podem se diferenciar das desta revista. 